\title{
CSN5 silencing reverses sorafenib resistance of human hepatocellular carcinoma HepG2 cells
}

\author{
HAIBO WANG $^{1 *}$, ZHENGYAO QIAN $^{2 *}$, HUI ZHAO $^{3 *}$, XIBO ZHANG $^{1}$, SHUQIANG CHE $^{4}$, HONGTAO ZHANG $^{1}$, \\ HAITAO SHANG ${ }^{1}$, JIANHENG BAO ${ }^{1}$, CHENGFEI HAO ${ }^{1}$, JUNJIAN LIU ${ }^{1}$ and ZHONGLIAN LI ${ }^{1}$ \\ ${ }^{1}$ Department of Hepatobiliary and Pancreatic Surgery (2), Tianjin Nankai Hospital, Tianjin 300100; \\ ${ }^{2}$ Department of Cardiology, Tianjin Hospital, Tianjin 300211; ${ }^{3}$ Tianjin Entry-Exit Inspection and Quarantine Bureau, \\ International Travel Healthcare Center, Tianjin 300456; ${ }^{4}$ Department of Nephrology, \\ Tianjin Academy of Traditional Chinese Medicine Affiliated Hospital, Tianjin 300120, P.R. China
}

Received July 6, 2014; Accepted March 18, 2015

DOI: $10.3892 / \mathrm{mmr} .2015 .3871$

\begin{abstract}
Hepatocellular carcinoma (HCC) is one of the most common tumor types, and is the third leading cause of cancer mortalities worldwide. A large number of patients with $\mathrm{HCC}$ are diagnosed at a late stage when the curative treatment of surgical resection and liver transplantation are no longer applicable. Sorafenib has been proved to improve overall survival in advanced HCC; however, drug resistance is common. The present study reported that the CSN5 is correlated with sorafenib resistance of the HCC cell line HepG2/S. Following silencing of CSN5, resistance to sorafenib was reversed, and multi-drug-resistance proteins, including as adenosine triphosphate binding cassette (ABC) B1, ABCC2 and ABCG2 as well as CDK6, cyclin D1 and B-cell lymphoma 2 were downregulated. In addition, it was demonstrated that the integrin beta-1, transforming growth factor- $\beta 1$ and nuclear factor- $\kappa \mathrm{B}$ pathways were modified by CSN5.
\end{abstract}

\section{Introduction}

Hepatocellular carcinoma (HCC) is the most common type of tumor in the liver and was responsible for 696,000 mortalities worldwide in 2008 (1). The prognosis of patients with $\mathrm{HCC}$ is generally poor. Surgical resection and liver transplantation are curative strategies. However, most patients are diagnosed at a late stage, at which surgical resection or liver transplantation are no longer a treatment option. In addition,

Correspondence to: Dr Zhonglian Li, Department of Hepatobiliary and Pancreatic Surgery (2), Tianjin Nankai Hospital, 122 Sanwei Road, Tianjin 300100, P.R. China

E-mail: lizhonglian@medmail.com.cn

*Contributed equally

Key words: hepatocellular carcinoma, CSN5, drug resistance the shortage of liver donors and high expenses of surgery are major disadvantages. Unfortunately, HCC are intrinsically resistant to chemotherapy. A multi-drug chemotherapy regime known as Transcatheter Arterial Chemoembolization is used for treating unresectable tumors, but has little if any effects (2). The development of targeted therapies against HCC has progressed slower than those against leukemias, breast cancer and lung cancer (3). In 2008, the Sorafenib HCC Assessment Randomised Protocol trial showed that sorafenib, an anti-angiogenic and anti-proliferative agent, -improved overall survival in Child-Pugh class A patients with advanced HCC (4). Sorafenib is a multikinase inhibitor, which inhibits vascular endothelial growth factor receptor, platelet-derived growth factor receptor and Raf kinases $(5,6)$. This novel drug is soon to become the standard therapeutic for advanced HCC (7). However, this promising treatment has limited survival benefits and low rates of tumor response, suggesting that primary and acquired drug resistance are common (8). Therefore, it is important to identify the molecular mechanisms and possible targets for sorafenib resistance.

A large number of studies have been published to demonstrate the mechanisms of sorafenib resistance, focusing on the tumor cells themselves as well as the importance of tumor stroma or microenvironment (9). CSN5, the fifth subunit of COP9 signalosome, which is also known as JAB1 or COPS5, was reported to be involved in early progressive stages of HCC and to be able to serve as a therapeutic target $(10,11)$. CSN5 is the catalytic center of CSN, acts as a modulator of intracellular signaling, and affects cellular proliferation and apoptosis (12). These characteristics of CSN5 endue it an oncogenic nature in cancer. The present study investigated the role of CSN5 in sorafenib resistance of the HCC cell line HepG2 using small interfering RNA (siRNA)-mediated CSN5 knockdown. The involvement of several adenosine triphosphate binding cassette (ABC) family transporters and a number of cell cycle- and apoptosis-associated proteins in this modulation was also assessed; furthermore, the involvement of transforming growth factor (TGF)- $\beta 1$ and nuclear factor $(\mathrm{NF})-\kappa \mathrm{B}$ pathways was assessed using ELISA and a luciferase reporter assay, respectively. 


\section{Materials and methods}

Cell culture and establishment of sorafenib-resistant Hep G2/S cells. The HCC cell line HepG2 was obtained from the Cell Bank of the Chinese Academy of Science (Shanghai, China) and maintained at $37^{\circ} \mathrm{C}$ in a humidified atmosphere with $5 \% \mathrm{CO}_{2}$. The culture medium was Eagle's minimal essential medium (EMEM) supplemented with $10 \%$ fetal bovine serum (FBS; Corning, Manassas, VA, USA). The sorafenib-resistant cell clone HepG2/S was established by continuing exposure of the parental cells to increasing concentrations of sorafenib (final concentration $1 \mu \mathrm{M}$; Sigma-Aldrich, St. Louis, MO, USA).

Silencing of CSN5 by siRNA. The CSN5 siRNA was synthesized by GeneChem Co, Ltd., (Shanghai, China) as described in the present study. The sequences of the siRNA were sense, 5'-GGAUCACCAUUACUUUAAGtt-3' and antisense, 5'-CUU AAAGUAAUGGUGAUCCtt-3'. Futhermore, scrambled siRNAs that do not target any endogenous gene transcript were also purchased from GeneChem Co., Ltd. The sequences were as follows: 5'-GCACCGTGACTATGtt-3' and 5'-GAT CCAAAAACTTCtt-3'. A total of $2 \times 10^{5}$ cells were seeded into six-well plates for $24 \mathrm{~h}$ in culture medium. The wells were washed once with siRNA transfection medium (Santa Cruz Biotechnology, Inc., Dallas, TX, USA). For each transfection, $0.8 \mathrm{ml}$ siRNA transfection medium containing $20 \mathrm{nM}$ siRNA was added. After $24 \mathrm{~h}$ of incubation, $1 \mathrm{ml}$ normal growth medium was added and the cells were incubated for another $24 \mathrm{~h}$. The medium was aspirated and replaced with fresh normal growth medium (10\% FBS) and the subsequent assays were performed 24-72 h after the replacement of normal growth medium. Scrambled siRNA transfection was performed following the same protocols.

MTS assay. A total of $1 \times 10^{5} / \mathrm{ml}$ cells in $0.1 \mathrm{ml}$ medium were seeded into each well of a 96-well microplate and incubated overnight to achieve cell adherence. Various concentrations of sorafenib were then added to each well and the cells were cultured for another 72 h. CellTiter 96 Aqueous One solution reagent (Promega Corp., Madison, WI, USA) was used according to the manufacturer's instructions. Following $4 \mathrm{~h}$ of incubation the cell viability was determined by measuring the absorbance at $490 \mathrm{~nm}$ using a microplate reader (MK3; BIO-DL Corporation, Plano, TX, USA).

Flow cytometric analysis of intracellular accumulation of rhodamine-123, cell cycle distribution and apoptotic rate. Approximately $1 \times 10^{6}$ cells were harvested and re-suspended in $0.1 \mathrm{ml}$ culture medium. The cells were stained with $10 \mu \mathrm{M}$ rhodamine-123 (Sigma-Aldrich) for $1 \mathrm{~h}$ and its intracellular concentration was determined by flow cytometry. For cell cycle analysis, $\sim 5 \times 10^{3}$ cells were cultured in a six-well microplate for $24 \mathrm{~h}$, followed by harvesting and fixation in ethanol overnight at $4^{\circ} \mathrm{C}$. Cells were then re-suspended in $1 \mathrm{ml}$ phosphate-buffered saline (PBS; Sigma-Aldrich) and propidium iodide (PI; Sigma-Aldrich) was used to stain DNA for $30 \mathrm{~min}$. The cell cycle was determined by flow cytometry. For determination of the apoptotic rate, $\sim 5 \times 10^{3}$ cells were cultured in a six-well microplate for $24 \mathrm{~h}, 10 \mu \mathrm{M}$ sorafenib was added and cells were cultured for another $24 \mathrm{~h}$. Cells were harvested, re-suspended in $0.1 \mathrm{ml}$ culture medium and incubated with Annexin V-fluorescein isothiocyanate/PI dual stain (BD Biosciences, San Jose, CA, USA) was for $15 \mathrm{~min}$ according to the manufacturer's instructions. Cell apoptosis was determined by flow cytometry (ARIA II; BD Biosciences, Franklin Lakes, NJ, USA).

Reverse transcription quantitative polymerase chain reaction $(R T-q P C R)$ analysis. A total of $3 \times 10^{6}$ cells were harvested for RT-PCR analysis. Total mRNA was extracted from the cells using the Dynabeads mRNA Direct kit (Invitrogen Life Technologies, Carlsbad, CA, USA) according to the manufacturer's instructions. Total mRNA was then reverse transcribed for $1 \mathrm{~h}$ at $42^{\circ} \mathrm{C}$ in incubation buffer containing $250 \mu \mathrm{M}$ of each deoxynucleotide triphosphate, $5 \mu \mathrm{M}$ oligo (dT) 20, 25 units of RNase inhibitor (Promega) and 20 units of avian myeloblastosis virus reverse transcriptase (Roche Diagnostics, Basel, Switzerland). The transcription level of target proteins was detected by semiquantitative real-time PCR using the icycler iQ detection system (Bio-Rad Laboratories, Inc., Hercules, CA, USA). The PCR conditions were as follows: Decontamination at $50^{\circ} \mathrm{C}$ for $2 \mathrm{~min}$, denaturation at $95^{\circ} \mathrm{C}$ for $2 \mathrm{~min}$, followed by 35 cycles at $95^{\circ} \mathrm{C}$ for $20 \mathrm{sec}$ and at $65^{\circ} \mathrm{C}$ for $40 \mathrm{sec}$. The primer sequences were as follows: ABCB1 forward, 5'-AAAAAGATCAACTCGTAC CACTC-3' and reverse, 5'-GCACAAAATACACCAACAA-3'; ABCC2 forward, 5'-CTGGGAACATGATTAGGAAGC-3' and reverse, 5'-GAGGATTTCCCAGAGCCGAC-3'; ABCG2 forward, 5'-GGGTTC TCT TCTTCCTGACGACC-3' and reverse, 5'-CAGACAACCAGTTAGAGTGTTGGT-3'; CDK6 forward, 5'-GCCTATGGGAAGGTGTTCAA-3' and reverse, 5'-CACTCCAGGCTCTGGAACTT-3'; cyclin D1 forward, 5'-CTGGAGCCCGTGAAAAAGAGC-3' and reverse, 5'-CTGGAGAGGAAGCGTGTGAGG-3'; integrin beta-1 (ITGB1) forward, 5'-CAAAGGAACAGCAGAGAAGC-3' and reverse, 5'-ATTGAGTAAGACAGGTCCATAAGG-3'; B-cell lymphoma 2 (Bcl-2) forward, 5'-ACGGGGTGAACT GGGGGAGGA-3' and reverse, 5'-TGTTTGGGGCAGGCA TGTTGACTT-3'; $\beta$-actin (internal control) forward, 5'-TGA GCGCGGCTACAGCTT-3' and reverse, 5'-TCCTTAATG TCACGCACGATTT-3'. Primers were synthesized by Sangon Biotech (Shanghai, China).

Western blot analysis. The total protein was obtained by radioimmunoprecipitation lysis buffer (Millipore, Billerica, MA, USA) extraction and centrifugation at $12,000 \mathrm{xg}$ for $10 \mathrm{~min}$. Total protein concentrations of the supernatants were measured using a bicinchoninic acid kit (Sigma-Aldrich). $100 \mu \mathrm{g}$ protein was separated by $12 \%$ SDS-PAGE (Beyotime Institute of Biotechnology, Shanghai, China) and transferred onto polyvinylidene difluoride membranes (Millipore). Target proteins were detected by incubation overnight at $4^{\circ} \mathrm{C}$ with rabbit anti-ABCB1 (cat. no. sc-8313; 1:1,500), rabbit anti-ABCC2 (cat. no. sc-20766; 1:1,500), rabbit anti-ABCG2 (cat. no. sc-25822; 1:1,500), rabbit anti-Bcl-2 (cat. no. sc-492; 1:1,500), rabbit anti-CDK6 (cat. no. sc-177; 1:1,500), rabbit anti-cyclin D1 (cat. no. sc-753; 1:1,500), mouse anti-ITGB1 (cat. no. sc-13590; 1:1,500), rabbit anti-NF-кB (p65) (cat. no. sc-372; 1:1,500), goat anti-Smad2 




Figure 1. Expression of CSN5 in human hepatocellular carcinoma cell line HepG2/S. (A) Quantitative polymerase chain reaction analysis and (B) western blot analyses were performed to detect CSN5 expression of HepG2 cells (parent), HepG2/S cells (control), HepG2/S cells transfected with scrambled siRNA (negative) or CSN5-siRNA (siRNA1, siRNA2). Values are expressed as the mean \pm standard deviation $(n=5) .{ }^{\wedge}$ Compared to the parent group $(\mathrm{P}<0.05) ;{ }^{*}$ compared to the control group $(\mathrm{P}<0.05)$. si, small interfering.

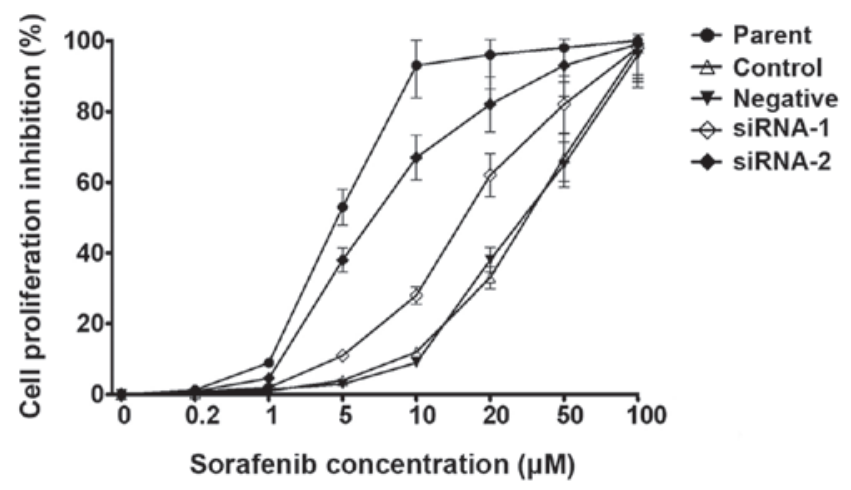

Figure 2. Knockdown of CSN5 restores sorafenib sensitivity in HepG2/S cells. MTS assay was performed to assess the effect of CSN5 on sorafenib sensitivity of HepG2 cells (parent), HepG2/S cells (control), HepG2/S cells transfected with scrambled siRNA (negative) or CSN5-siRNA (siRNA1, siRNA2). Values are expressed as the mean \pm standard deviation $(n=10)$. si, small interfering.

(cat. no.sc-6200; 1:1,500), goat anti-phosphorylated (p-)Smad2 (cat. no. sc-11769; 1:1,000), rabbit anti-Smad3 (cat. no. 8332; 1,1,500), rabbit anti-p-Smad3 (cat. no. sc-130218; 1:1,000) and goat anti- $\beta$-actin (cat. no. sc-1616; 1:5,000) antibody (Santa Cruz Biotechnology, Inc.). All primary antibodies were diluted according to the manufacturer's instructions. Membranes were washed and incubated for $1 \mathrm{~h}$ with peroxidase-labeled anti-rabbit immunoglobulin (Ig)G (Santa Cruz Biotechnology, Inc.; diluted at 1:2,000). Finally, membranes were washed three times with $0.1 \mathrm{M}$ Tris-HCl, (pH 9.5) $50 \mathrm{mM} \mathrm{MgCl}_{2}$, $0.1 \mathrm{M} \mathrm{NaCl}, 0.1 \%$ Tween-20 [0.1\%(v/v)] and exposed to the Immobilon $^{\mathrm{TM}}$ Western chemiluminescent horseradish peroxidase substrate (Carestream, Shanghai, China) for $1 \mathrm{~min}$, and then exposed autoradiography film for 2-3 min in the dark.

ELISA. Cell supernatants were collected and TGF- $\beta 1$ levels were measured using a human TGF- $\beta$ ELISA kit according to the manufacturer's instructions (R\&D Systems, Inc., Minneapolis, MN, USA).
$N F-\kappa B$ transcriptional activity assay. The activity of $\mathrm{NF}-\kappa \mathrm{B}$ was determined by a reporter gene system (Bright-Glo ${ }^{\mathrm{TM}}$ Luciferase assay system; Promega) according to the manufacturer's instructions with moderate modifications. Briefly, the assays were performed in a 96 -well plate. $1 \times 10^{4}$ viable cells were seeded into each well in triplicate and incubated overnight to allow for the adherence of the cells. To transfect the cells, $0.1 \mu \mathrm{g}$ pGL 4.32[luc2P/NF-kB-RE/Hypro] plasmids (Promega) was added. The plasmids contained five copies of an $\mathrm{NF}-\kappa \mathrm{B}$ response element $(\mathrm{NF}-\kappa \mathrm{B}-\mathrm{RE})$ that drive the transcription of the luciferase reporter gene luc2P (Photinus pyralis). After $24 \mathrm{~h}$ of transfection, the luciferase activity was analyzed using the Bright-Glo ${ }^{\mathrm{TM}}$ Luciferase Assay System (Promega).

Statistical analyses. Values are expressed as the means \pm standard deviation. Statistical analysis was performed using Student's $t$-test (two-tailed) with SPSS 10.0 (SPSS, Inc., Chicago, IL, USA). P<0.05 was considered to indicate a statistically significant difference between values.

\section{Results}

Sorafenib-resistant HepG2/S cells overexpress CSN5. Sorafenib-resistant HepG2/S cell lines were established after 9.5 months of continuous exposure to sorafenib. The naive HepG2 cell line was named the parent group, the untreated sorafenib-resistant HepG2/S cell line was named the control group, the HepG2/S cell line transfected with scrambled siRNAs was named the negative group and theHepG2/S CSN5-silenced cell lines were named the siRNA-1 and siRNA-2 groups. PCR and western blot analyses showed that there was a significant CSN5 overexpression in the HepG2/S cell line compared with the parental HepG2 cell line; however, CSN5 expression was decreased in the CSN5-silenced groups (Fig. 1).

CSN5 silencing increases sorafenib sensitivity. The $\mathrm{IC}_{50^{-}}$ value of sorafenib to HepG2/S and HepG2 was $28.5 \mu \mathrm{M}$ and $4.2 \mu \mathrm{M}$, respectively, and the resistance factor of HepG2/S to sorafenib was 6.8 times that of parental cells. An MTS assay showed that the sensitivity of the cells to sorafenib increased after CSN5 silencing. The drug sensitivity of each group of cells was represented by an $\mathrm{IC}_{50}$-value. As shown in Fig. 2, the $\mathrm{IC}_{50}$-values on the CSN5-silenced cells (14.2 and 7.3 $\left.\mu \mathrm{M}\right)$ were lower than that on the HepG2/S cells. The negatively transfected cells were nearly unaffected by sorafenib. These results indicated that CSN5 has a role in the sorafenib resistance of HCCs.

CSN5 silencing restores drug sensitivity, enhances intracellular accumulation of rhodamine-123, causes cell cycle arrest, increases the apoptotic rate and modulates the expression of $A B C B 1, A B C C 2$ and $A B C G 2$. The intracellular drug concentration is a key factor that influences the effect of drugs. Rhodamine-123 is a widely used fluorescent dye to predict the potency of cancer cells to take up or eliminate drugs. Flow cytometric analysis showed that CSN5-silenced cells had a greater intracellular fluorescent activity, which meant that a larger quantity of rhodamine-123 was retained in the cell (Fig. 3A and B). Furthermore, flow cytometric analysis showed 

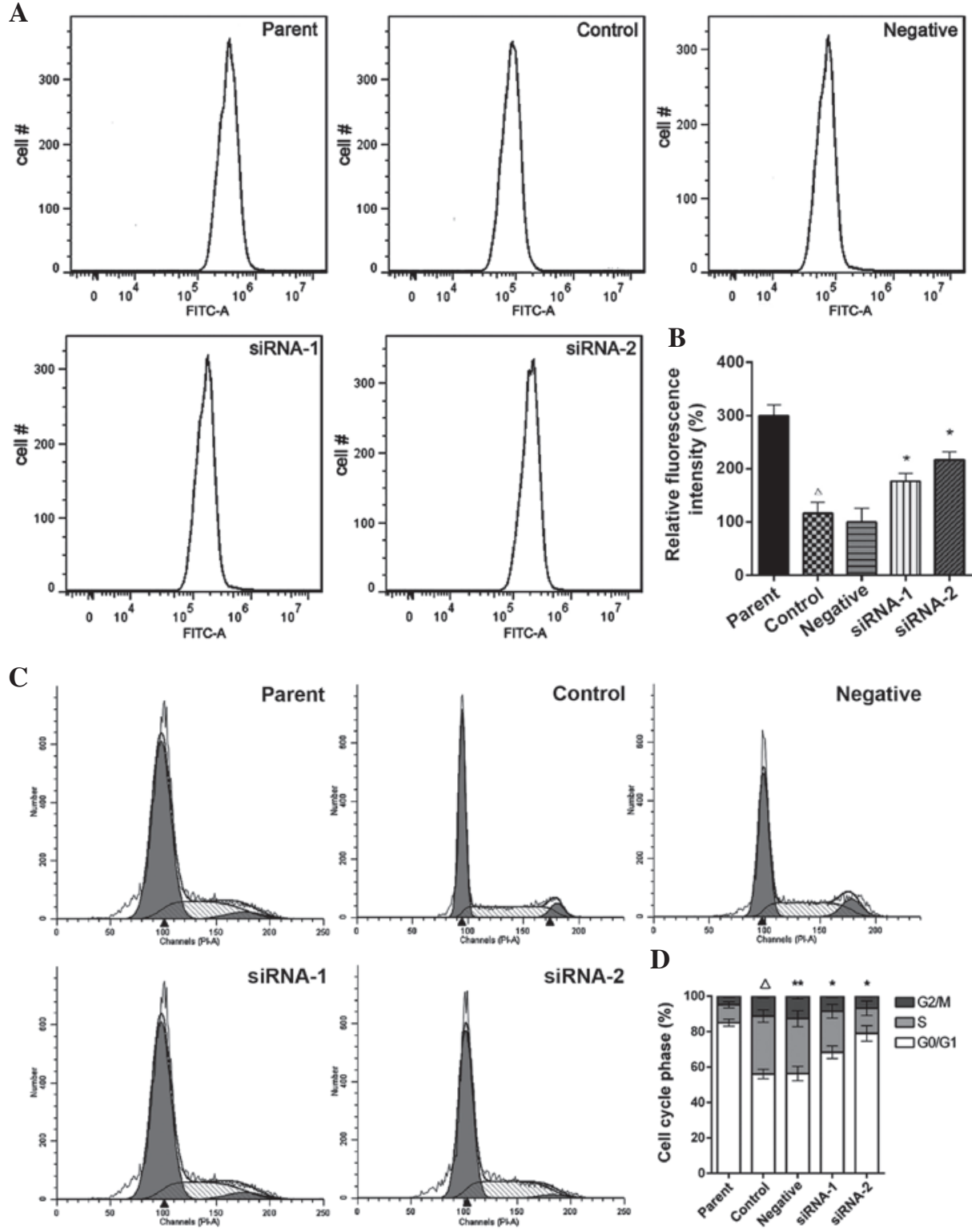

$\mathbf{E}$
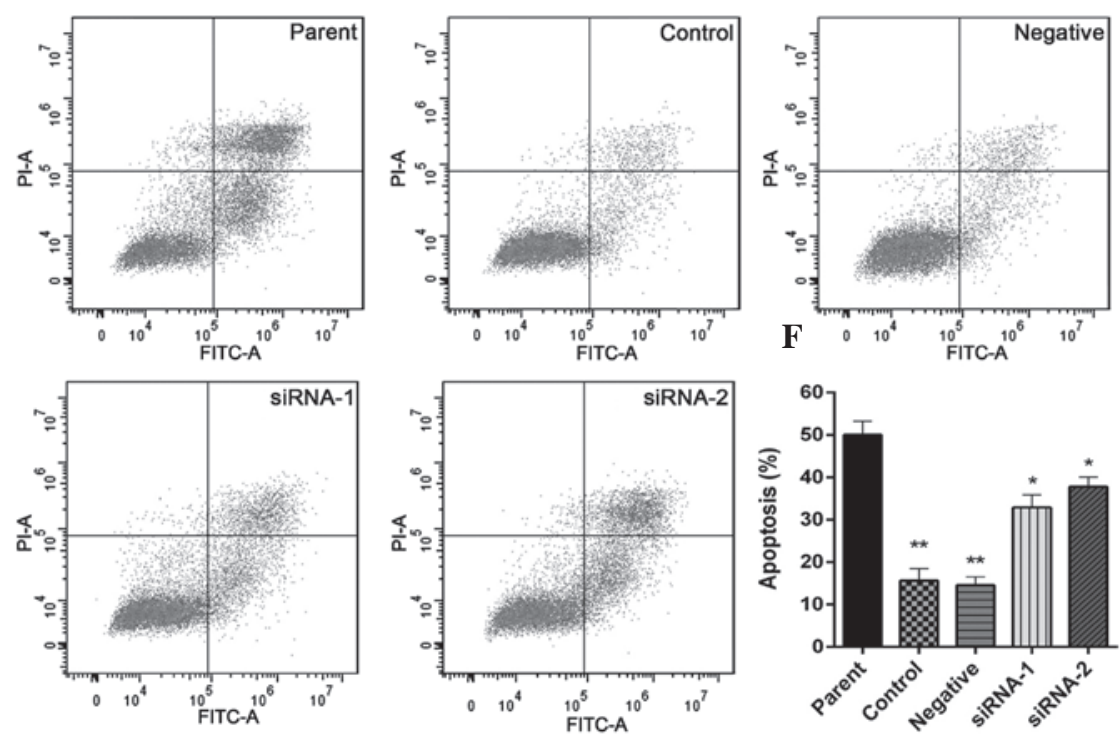

Figure 3. Knockdown of CSN5 restores sorafenib effects on intracellular accumulation of rhodamine-123, cell cycle arrest and apoptosis rate in HepG2/S cells. (A and B) Rhodmine-123 accumulation in HepG2 cells (parent), HepG2/S cells (control), HepG2/S cells transfected with scrambled siRNA (negative) or CSN5-siRNA (siRNA1, siRNA2). (C and D) Cell cycle analysis and (E and F) apoptosis analysis was performed after sorafenib (10 $\mu \mathrm{M})$ treatment for $24 \mathrm{~h}$. Values are expressed as the mean \pm standard deviation $(\mathrm{n}=3)$. ${ }^{\wedge}$ Compared to the parent group $(\mathrm{P}<0.05) ;{ }^{*}$ compared to the control group $(\mathrm{P}<0.05)$. si, small interfering; FITC, fluorescein isothiocyanate; PI, propidium iodide. 

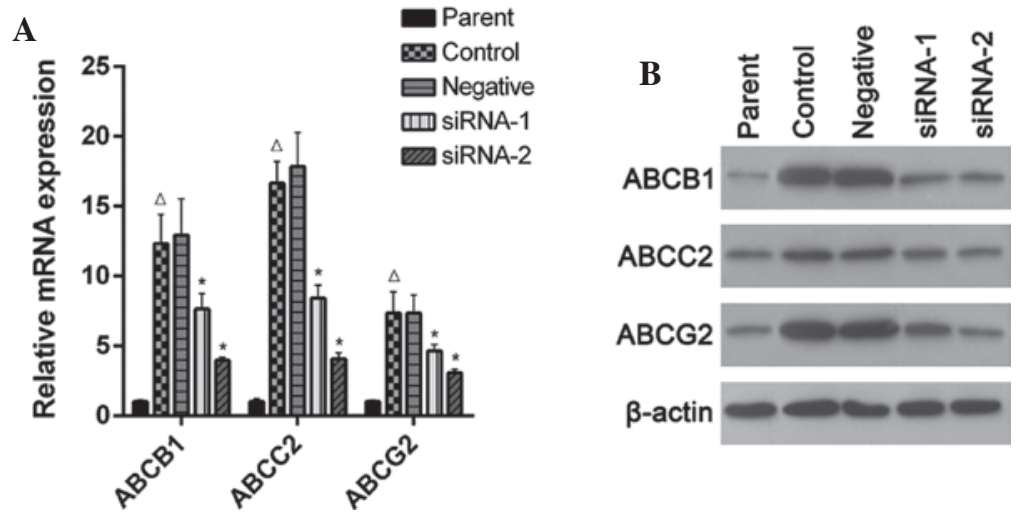

Figure 4. Knockdown of CSN5 downregulates ABC family proteins in HepG2/S cells. (A) Quantitative polymerase chain reaction analysis and (B) western blot assay were performed to detect ABC family expression of HepG2 cells (parent), HepG2/S cells (control), HepG2/S cells transfected with scrambled siRNA (negative) or CSN5-siRNA (siRNA1, siRNA2). Values are expressed as the mean \pm standard deviation ( $\mathrm{n}=5$ ). ${ }^{\wedge} \mathrm{Compared}$ to the parent group $(\mathrm{P}<0.05$ ); *compared to the control group $(\mathrm{P}<0.05)$. si, small interfering; $\mathrm{ABC}$, adenosine triphosphate binding cassette.
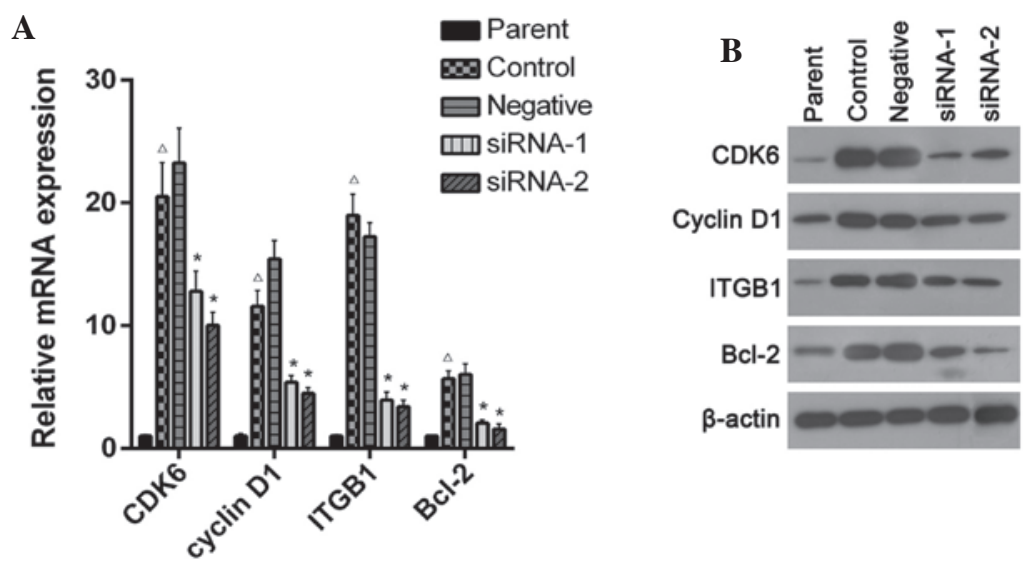

Figure 5. CSN5 modulates the expression of CDK6, cyclin D1, ITGB1 and Bcl-2 in HepG2/S cells. (A) Quantitative polymerase chain reaction analysis and (B) western blot analyses were performed to detect CDK6, cyclin D1, ITGB1 and Bcl-2 expression of HepG2 cells (parent), HepG2/S cells (control), HepG2/S cells transfected with scrambled siRNA (negative) or CSN5-siRNA (siRNA1, siRNA2). Values are expressed as the mean \pm standard deviation ( $\mathrm{n}=3$ ). ${ }^{4}$ Compared to the parent group ( $\left.\mathrm{P}<0.05\right)$; ${ }^{*}$ compared to the control group $(\mathrm{P}<0.05)$. ITGB1, integrin beta-1; Bcl-2, B-cell lymphoma 2; si, small interfering.
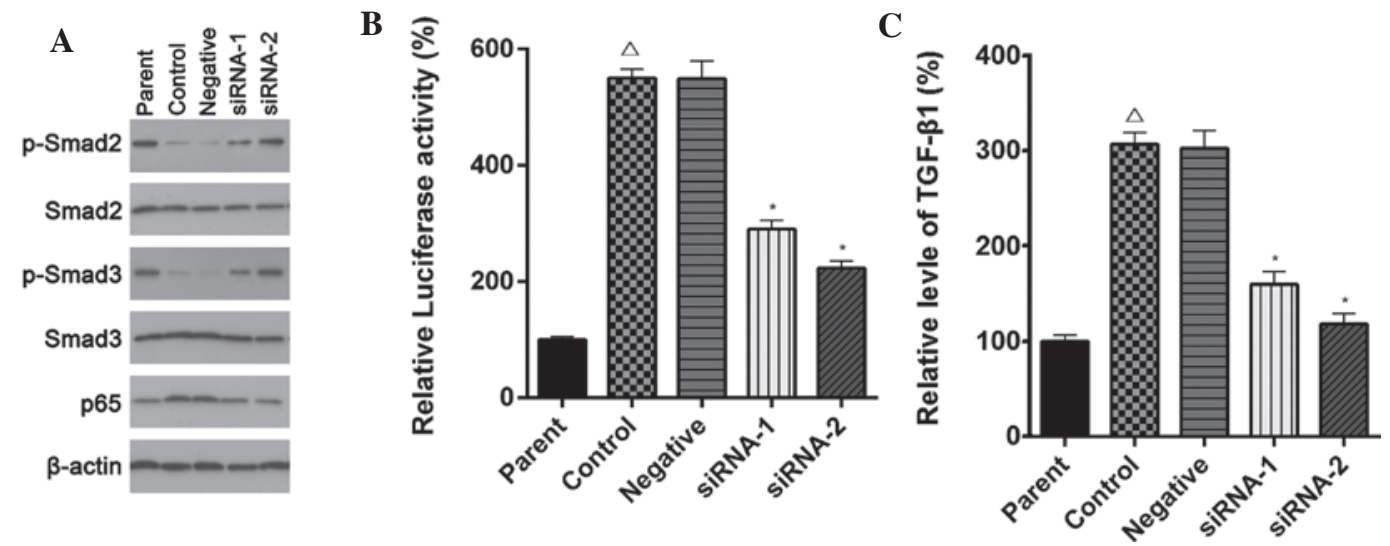

Figure 6. CSN5 modulates TGF- $\beta 1$ and NF-kB pathway activity in HepG2/S cells. Effects of CSN5 knockdown on (A) phospho-Smad2/3 and p65 levels, (B) transcriptional activity of NF- $\mathrm{KB}$ and (C) TGF- $\beta 1$ levels of HepG2 cells (parent), HepG2/S cells (control), HepG2/S cells transfected with scrambled siRNA (negative) or CSN5-siRNA (siRNA1, siRNA2). Values are expressed as the mean \pm standard deviation $(\mathrm{n}=3) .{ }^{\wedge} \mathrm{Compared}$ to the parent group $(\mathrm{P}<0.05)$; "compared to the control group $(\mathrm{P}<0.05)$. TGF, transforming growth factor; NF- $\mathrm{kB}$, nuclear factor kappa $\mathrm{B}$; si, small interfering.

that the cell cycle was halted at G0/G1 phase (Fig. 3C and D) and the apoptotic rate increased significantly following CSN5 silencing, as shown in Fig. 3E and F.
As flow cytometric analysis showed that intracellular rhodamine-123 increased after CSN5 silencing, it was further investigated whether the expression of transporters from the $\mathrm{ABC}$ 
family, including ABCB1, ABCC2 and ABCG2, which have the potency to transport rhodamine-123 as well as sorafenib, were modulated. Western blot and RT-PCR analyses showed that HepG2/S cells expressed increased levels of ABCB1, ABCC2 and ABCG2 compared with those in parental HpeG2 cells, whereas the expression of the above proteins was decreased in the CSN5-silenced cells Fig. 4.

CSN5 silencing decreases the expression of CDK6, cyclin D1, ITGB1 and Bcl-2. CDK6 and cyclin D1 are two critical molecules that are involved in G1/S phase transition. ITGB1 is involved in cancer cell proliferation and evasion of apoptosis. $\mathrm{Bcl}-2$ has been implicated in the evasion of apoptosis and is also thought to be involved in resistance to conventional cancer treatment. The expression of CDK6, cyclin D1, ITGB1 and Bcl-2 was upregulated in HepG2/S cells when compared to that in the parental cells. Silencing of CSN5 markedly downregulated the expression of these proteins. The RT-PCR results were consistent with the results of the western blot analysis, as shown in Fig. 5.

CSN5 modulates TGF- $\beta 1$ and $N F-\kappa B$ pathways. Western blot analysis revealed that CSN5 silencing increased the phosphorylation of Smad 2/3, which are two key mediators of the TGF- $\beta 1$ pathway. The luciferase reporter system showed that transcriptional activity of $\mathrm{NF}-\kappa \mathrm{B}$ was decreased by CSN5 silencing. Furthermore, western blot analysis indicated that the expression of NF- $\kappa \mathrm{B}$ p 65 was downregulated, which may have contributed to the decrease of NF- $\kappa \mathrm{B}$ activity (Fig. 6).

\section{Discussion}

HCC is the most common type of liver cancer. Systemic therapy is of great important, since more than half of the patients with $\mathrm{HCC}$ are diagnosed at an advanced stage at which surgical intervention is inapplicable. However, the response rate to traditional cytotoxicity-based drug regimes is low (13). After a large-scale phase three clinical trial demonstrated a number of overall survival benefits, sorafenib, a multikinase inhibitor, quickly became the standard therapeutic. However, primary and acquired resistances of HCC to sorafenib are common. The present study demonstrated the role of CSN5 in HCC cell resistance to sorafenib.

Sorafenib is a multi-functional drug. It blocks HCC cell proliferation, induces apoptosis of HCC cells and prevents tumor-associated angiogenesis. In the present study, a resistance effect based on the cancer cell proliferation and apoptosis was investigated. Sorafenib-resistant cell clones (HepG2/S) were established by continuous exposure of cultured cells to sorafenib. The results showed that HepG2/S cell lines overexpressed CSN5, the target protein of interest. To confirm the role of CSN5 in sorafenib resistance, CSN5 was silenced by siRNA, which was found to be able to restore the cells' sensitivity to sorafenib. Further investigation showed that after CSN5 silencing, intracellular accumulation of rhodamine-123 increased, the cell cycle was arrested in G0/G1 phase and the apoptotic rate was increased. These clues were taken as a basis for exploring the mechanism of CSN5-knockdown-mediated reversal of sorafenib resistance.

Only drug molecules that are taken up into the cancer cells exert their direct anti-tumor effects. One major mechanism involved in drug resistance is increased drug efflux by the cancer cells (14). The observed increase of the intracellular concentration of rhodamine-123 following CSN5 knockdown indicated that the drug efflux by the cancer cells was inhibited. Drug efflux is largely mediated by the ABC superfamily. It has been reported that sorafenib is efficiently transported by ABCG2 (15). However, there is a certain controversy regarding the transport effect of $\mathrm{ABCB} 1$; certain studies reported that sorafenib was moderately transported by ABCB1 (16), while other studies reported that sorafenib inhibited ABCB1 but did not appear to be ABCB1 substrates in vitro and cancer cells transfected with $\mathrm{ABCC} 2$ (also called MRP2) had increased resistance to sorafenib, which suggested that sorafenib is a substrate for ABCC2 $(17,18)$. The present study demonstrated that CSN5 silencing downregulated the expression of these $\mathrm{ABC}$ family transporters. Hence, this effect was able to enhance the intracellular concentration of sorafenib.

CDK6 is a key regulator in G1/S-phase transition, and is functionally associated with TGF- $\beta 1$ (19). Cyclin D1 forms a complex with CDK6 and functions as a regulatory subunit to promote G1/S-phase transition (20). The results of the present study were consistent with those reported previously that CSN5 silencing was able to downregulate CDK6 and cyclin D1 expression and arrest the cell cycle at G0/G1 phase. ITGB1 functionally interacts with key cancer regulators, including MYC and TGF- $\beta 1$, and is involved in the control of proliferation, apoptosis and HCC progression $(21,22)$. Thus CSN5 silencing-mediated ITGB1 down-regulation in HepG2/S may have contributed to the observed cell cycle arrest and increase in the apoptotic rate. Bcl-2 is an anti-apoptosis protein and its overexpression is correlated with drug resistance (23). The results of the present study demonstrated that $\mathrm{Bcl}-2$ was involved in sorafenib resistance in HepG2/S, as it was down-regulated following CSN5 silencing.

The reporter gene system showed that transcriptional activity of NF- $\kappa \mathrm{B}$ was downregulated after CSN5 silencing. Western blot analysis indicated that this modification may proceed via downregulation of the expression of $N F-\kappa B$ p65. The present study also suggested that CSN5 silencing activated the TGF- $\beta 1$ pathway, as the phosphorylation of Smad $2 / 3$ was elevated. The TGF- $\beta$ pathway is one of the most complex pathways in cancer regulation and has the potential to either prevent or promote cancer progression. Smad $2 / 3$ is situated downstream of TGFBR2 and is able to inhibit cancer cell proliferation and induce apoptosis (24).

In conclusion, the results of the present study showed that CSN5 overexpression was a cause of sorafenib resistance of HCC. CSN5 silencing enhanced drug uptake, cell cycle arrest and apoptotic cell death. The present study suggested that activation of the TGF- $\beta 1$ signaling and inhibition of the $\mathrm{NF}-\kappa \mathrm{B}$ pathway may be critical for sorafenib resistance reversal following CSN5 inactivation.

\section{References}

1. Agarwal S, Sane R, Ohlfest JR and Elmquist WF: The role of the breast cancer resistance protein (ABCG2) in the distribution of sorafenib to the brain. J Pharmacol Exp Ther 336: 223-233, 2011.

2. Berasain C: Hepatocellular carcinoma and sorafenib: too many resistance mechanisms? Gut 62: 1674-1675, 2013. 
3. Zhu Y, Zhu L, Lu L, Zhang L, Zhang G, Wang Q and Yang P: Role and mechanism of the alkylglycerone phosphate synthase in suppressing the invasion potential of human glioma and hepatic carcinoma cells in vitro. Oncol Rep 32: 431-436, 2014.

4. Lee C, Lee C, Lee S, Siu A and Ramos DM: The cytoplasmic extension of the integrin $\beta 6$ subunit regulates epithelial-to-mesenchymal transition. Anticancer Res 34: 659-664, 2014.

5. Ferlay J, Shin HR, Bray F, Forman D, Mathers C and Parkin DM: Estimates of worldwide burden of cancer in 2008: GLOBOCAN 2008. Int J Cancer 127: 2893-2917, 2010.

6. Gauthier A and Ho M: Role of sorafenib in the treatment of advanced hepatocellular carcinoma: An update. Hepatol Res 43: 147-154, 2013.

7. Alam H, Kundu ST, Dalal SN and Vaidya MM: Loss of keratins 8 and 18 leads to alterations in $\alpha 6 \beta 4$-integrin-mediated signalling and decreased neoplastic progression in an oral-tumour-derived cell line. J Cell Sci 124: 2096-2106, 2011.

8. Ikushima $\mathrm{H}$ and Miyazono K: TGFbeta signalling: a complex web in cancer progression. Nat Rev Cancer 10: 415-424, 2010.

9. Rigalli JP, Ciriaci N, Arias A, Ceballos MP, Villanueva SS Luquita MG, Mottino AD, Ghanem CI, Catania VA and Ruiz ML: Regulation of multidrug resistance proteins by genistein in a hepatocarcinoma cell line: impact on sorafenib cytotoxicity. PLoS One 3: e0119502, 2015.

10. Kaposi-Novak P, Libbrecht L, Woo HG, Lee YH, Sears NC, Coulouarn C, Conner EA, Factor VM, Roskams T and Thorgeirsson SS: Central role of c-Myc during malignant conversion in human hepatocarcinogenesis. Cancer Res 69: 2775-2782, 2009.

11. Kim JK and Diehl JA: Nuclear cyclin D1: an oncogenic driver in human cancer. J Cell Physiol 220: 292-296, 2009.

12. Kollmann K, Heller G, Schneckenleithner C, Warsch W, Scheicher R, Ott RG, Schäfer M, Fajmann S, Schlederer M, Schiefer AI, Reichart U, et al: A kinase-independent function of CDK6 links the cell cycle to tumor angiogenesis. Cancer Cell 24: 167-181, 2013.

13. Lagas JS, van Waterschoot RA, Sparidans RW, Wagenaar E, Beijnen JH and Schinkel AH: Breast cancer resistance protein and P-glycoprotein limit sorafenib brain accumulation. Mol Cancer Ther 9: 319-326, 2010
14. Qiu JG, Zhang YJ, Li Y, Zhao JM, Zhang WJ, Jiang QW, Mei XL, Xue YQ, Qin WM, Yang Y,Zheng DW, Chen Y, Wei MN and Shi Z: Trametinib modulates cancer multidrug resistance by targeting ABCB1 transporter. Oncotarget Apr 14, 2015. [Epub ahead of print]

15. Lee YH, Judge AD, Seo D, Kitade M, Gómez-Quiroz LE, Ishikawa T, Andersen JB, Kim BK, Marquardt JU, Raggi C, Avital I, et al: Molecular targeting of CSN5 in human hepatocellular carcinoma: a mechanism of therapeutic response. Oncogene 30: 4175-4184, 2011.

16. Brózik A, Hegedüs C, Erdei Z, Hegedus T, Özvegy-Laczka C, Szakács G and Sarkadi B: Tyrosine kinase inhibitors as modulators of ATP binding cassette multidrug transporters: substrates, chemosensitizers or inducers of acquired multidrug resistance? Expert Opin Drug Metab Toxicol 5: 623-642, 2011.

17. Yagi K, Kawasaki Y, Nakamura H, Miura T, Takeda T, Esumi S, Matsunaga H, Kitamura Y and Sendo T: Differential combined effect of COX inhibitors on cell survival suppressed by sorafenib in the HepG2 cell line. Biol Pharm Bull 37: 1234-1240, 2014.

18. Sawyers CL: Shifting paradigms: the seeds of oncogene addiction. Nat Med 15: 1158-1161, 2009.

19. Shackleford TJ and Claret FX: JAB1/CSN5: a new player in cell cycle control and cancer. Cell Div 18: 26, 2010.

20. Shibayama Y, Nakano K, Maeda H, Taguchi M, Ikeda R, Sugawara M, Iseki K, Takeda Y and Yamada K: Multidrug resistance protein 2 implicates anticancer drug-resistance to sorafenib. Biol Pharm Bull 34: 433-435, 2011.

21. Smalley KS, Xiao M, Villanueva J, Nguyen TK, Flaherty KT, Letrero R, Van Belle P, Elder DE, Wang Y, Nathanson KL and Herlyn M: CRAF inhibition induces apoptosis in melanoma cells with non-V600E BRAF mutations. Oncogene 28: 85-94, 2009.

22. Thomas MB, O'Beirne JP, Furuse J, Chan AT, Abou-Alfa G and Johnson P: Systemic therapy for hepatocellular carcinoma: cytotoxic chemotherapy, targeted therapy and immunotherapy. Ann Surg Oncol 15: 1008-1014, 2008.

23. Wilhelm SM, Adnane L, Newell P, Villanueva A, Llovet JM and Lynch M: Preclinical overview of sorafenib, a multikinase inhibitor that targets both Raf and VEGF and PDGF receptor tyrosine kinase signaling. Mol Cancer Ther 7: 3129-3140, 2008.

24. Yip KW and Reed JC: Bcl-2 family proteins and cancer. Oncogene 50: 6398-6406, 2008. 